\title{
The Influence of the Preparation Megamix-Zinc on Yield and Grain Quality of Spring Wheat
}

\author{
Vitaly Isaychev, Nikolay Andreev* and Fail Mudarisov \\ Ulyanovsk State Agrarian University, 1, Noviy Venets, 432017, Ulyanovsk, Russia
}

\begin{abstract}
The conducted study has shown a stimulating effect of foliar dressing of spring wheat plants with the preparation Megamix-zinc. It has been ascertained that it has a positive effect on such indicators as productivity and quality of spring wheat grain. The use of macro and microelement-containing preparations in modern technologies of spring wheat cultivation has a positive influence on such indicators as yield, protein content in grain, quantity and quality of gluten, mass fraction of starch in grain.
\end{abstract}

\section{Introduction}

Numerous factors can be of crucial importance in the productivity of agricultural crops, including the use of pre-sowing cultivation and foliar dressing with macroand microelement-containing fertilizers in the agricultural technology.

An increase in the adaptive potential of cultivated plants, understood as a specific feature of ontogenetic adaptation to changing environmental conditions, relates to the production of agricultural produce. The study of the features essential to the formation of potential productivity and environmental sustainability, as well as their ratio, is considered as an important condition for the development of effective methods of managing the adaptive potential of cultivated plants [1].

Mineral nutrition of plants is the main factor that can be regulated for the purposeful management of plant growth and development in order to grow a high yield of good quality. Along with the main elements (nitrogen, phosphorus, potassium, sulfur, magnesium), microelements play a major role in plant nutrition. The intake of microelements by plants and their accumulation can vary widely, which is explained by the influence of specific soil and climatic conditions. In addition, the plants themselves are selective in absorbing trace elements. The process of trace element intake depends on the biological characteristics of plants, the biochemical composition and the strength of the bond of ions with cell membranes. It is also necessary to take into account the mutual influence of some trace elements on the change in the content of others (antagonism and synergism of ions).

The diverse and significant role of trace elements for plants is due to their participation in complex biological and physiological processes. They intensify the activity of enzymes, vitamins, hormones, they are linked with the processes of synthesis of organic substances, help to increase the productivity of crops and improve product quality.

The deficiency of trace elements in plants is primarily due to the low availability of the mobile forms of these elements in arable soil. The balance of trace elements in soils can be improved by increasing the amount of organic fertilizer application and the use of complex mineral fertilizers containing trace elements.

At present, the application issues of growth regulators and their physiological effects on plants have been examined $[2,3]$. The influence of microelements and natural phyto regulators on the growth processes and the formation of the yield and quality of agricultural crops was studied in the conditions of the forest-steppe of the Middle Volga region. In the territorial conditions of the Volga region, as well as in the country, there is no complete data to substantiate the theoretical and practical aspects of the use of chemical compounds that possess physiological activity in increasing the adaptation of plants in the agrocenosis. It is extremely important to develop systems for managing the productivity and resistance of plants, energy-saving technologies to produce ecologically safe crop produce [4]. In this regard, there is a necessity to study and substantiate scientifically the use of complex macro- and microelement preparations in the technology of spring wheat cultivation.

\section{Materials and methods}

The studies to determine the effectiveness of foliar dressing of spring wheat with the Megamix-zinc preparation were carried out in 2018-2020 in the experimental field of Ulyanovsk State Agrarian University. The soil of the experimental plot is black soil, leached, medium-thick, medium-loamy, with the following agrochemical characteristics: humus content $4.3 \%, \mathrm{PH}-5.8-6.8$, content of mobile phosphorus and

\footnotetext{
Corresponding author: andreev919@yandex.ru
} 
potassium, respectively $107-142$ and $103-135 \mathrm{mg} / \mathrm{kg}$ of soil, the degree of saturation with bases is $96.4-97.9 \%$, the number of absorbed bases is $25.5-27.8 \mathrm{mg}-$ eq. per $100 \mathrm{~g}$ of soil. The object of the study is the soft spring wheat variety "Ulyanovskaya 100".

The cultivation technology of spring wheat was based on agrotechnical practices generally accepted in the Ulyanovsk region. The plot area was $20 \mathrm{~m}^{2}$, the experiment was repeated four times, the arrangement of the plots was randomized. The application of a complex mineral fertilizer (nitroammofoska 16:16:16) at a dose of $\mathrm{N}_{30} \mathrm{P}_{60} \mathrm{~K}_{60}$ was carried out manually, according to the scheme of the experiment for pre-sowing cultivation. The sowing of the experimental crop was carried out at the optimal time (April 25 - May 1) by drilling to a depth of $5-6 \mathrm{~cm}$. The seeding rate was 5.5 million germinating seeds / ha or $220 \mathrm{~kg} /$ ha in physical mass.

The analysis of weather conditions during the growing season shows their relative stability over the years of studies, which contributes to the actualization of the biological potential of spring wheat plants. However, the year 2019 was characterized by a lack of moisture in the initial period of plant growth and development. In April - May, the amount of precipitation was only $37 \%$ of the norm. But in June and July, the rainfall was higher, which gave the plants an opportunity to develop.

The experiment was carried out in accordance with the generally accepted methods [5] according to the scheme: 1 - Without dressing (Control 1); 2 - Foliar dressing Megamix zinc (double) in the tillering phase + shooting; 3 - Without dressing (Control 2) in contrast to NPK; 4 - Foliar dressing Megamix - Zinc (double) in the tillering phase + shooting phase in contrast to NPK. The dressing of crops with the studied preparations was carried out in the concentrations recommended by the manufacturer $(0.5 \mathrm{l} / \mathrm{ha})$. The application of experimental preparations can be carried out simultaneously with the use of herbicides at the rate of 200 liters of working solution per 1 hectare or as a separate technological operation.

"Megamix-zinc" has a high content of zinc and it is used, as a rule, for foliar dressing of crops with an increased removal of this element. It raises water retention and absorption of phosphorus, prevents the development of signs of zinc deficiency - interveinal chlorosis, slow growth. The preparation has a high sulfur content, which increases the efficiency of tank mixtures with nitrogen fertilizers. Composition $\mathrm{g} / \mathrm{l}$ : $\mathrm{N}-70.0, \mathrm{~S}-$ 68.5, $\mathrm{Zn}-140$ [6].

The analyses, records and observations in the experiment were carried out in accordance with generally accepted methods and state standards. Field and laboratory experiments were accompanied by appropriate observations, records, and analyses.

\section{Research results}

Yield is a complex indicator of the implementation of the totality of physiological and biochemical processes realized during the growing season of a crop. This process is dependent on climatic conditions, genomic potential, agricultural technology, the use of fertilizers, microelements and phyto regulators. A rise in plant metabolism contributes to the stable state of the organism in unfavorable environmental conditions, the effective use of the basic elements of mineral nutrition, which contributes to the formation of increased yield while maintaining the satisfactory quality of grain. Yield largely depends on weather conditions (temperature and moisture conditions) during the growing season. To reduce risks, various agricultural practices are used in the technology of cultivation of agricultural crops. Foliar dressing of vegetative plants and pre-sowing treatment of seeds with preparations that have a growth-regulating and growth-stimulating effect, promotes the stimulation of growth processes from the early stages, and an increase in plant productivity [7].

The conducted studies have shown that the yield of spring wheat primarily depends on weather conditions. Unfavorable moisture conditions and high temperatures in 2019 during the seed germination period contributed to a decrease in yields by up to $15 \%$ compared to more stable and favorable weather conditions in 2020.

On average, during the research years, the studied modification of the preparation Megamix-zinc contributed to an increase in the yield by $1.43 \mathrm{c} / \mathrm{ha}$ in contrast to unfertilized plots, and by $3.12 \mathrm{c} / \mathrm{ha}$ compared with fertilized plots. The maximum result in relation to the control variant is provided by the modified preparation Megamix-zinc together with nitroammophoska, which is $11 \%$ (Table 1).

Table 1. Yield of the spring wheat variety "Ulyanovskaya $100 ", \mathrm{c} / \mathrm{ha}$

\begin{tabular}{|c|c|c|c|c|c|c|}
\hline \multirow{2}{*}{ Variant } & \multicolumn{4}{|c|}{ Yield } & \multicolumn{2}{|c|}{ Increase } \\
\hline & 2018 & 2019 & 2020 & Average & c/ha & $\%$ \\
\hline Control 1 & 30.34 & 24.28 & 30.58 & 28.40 & - & - \\
\hline Megamix-zinc & 32.85 & 2.50 & 31.15 & 29.83 & 1.43 & 5.0 \\
\hline $\begin{array}{c}\text { Control } 2+ \\
\text { NPK }\end{array}$ & 32.22 & 25.66 & 31.54 & 29.81 & 1.41 & 4.9 \\
\hline $\begin{array}{l}\text { Megamix- } \\
\text { zinc+ NPK }\end{array}$ & 34.10 & 26.98 & 33.48 & 31.52 & 3.12 & 11.0 \\
\hline $\mathrm{LSD}_{05}$ & 1.53 & 0.21 & 0.38 & & & \\
\hline
\end{tabular}

The protein content is one of the main indicators of the quality of the final cereal produce. A large proportion of protein substances in grain is in the endosperm, and in solid form, as they reserve nutrients. In plants, protein substances are contained in a smaller amount than carbohydrates, but in the construction of plant tissues and the implementation of vital processes, they play a dominant role [8].

The positive effect of some microelements on the protein metabolism of plants has been proven. Manganese, zinc, cobalt, iron activate such enzymes of protein metabolism as arginase, lecithinase, aminopeptidase. Molybdenum and manganese are involved in the synthesis of amino acids from which proteins are formed. Quantitative and qualitative characteristics of protein in grain depend on many external and internal factors. They can be divided into two groups: the first one-factors that cannot be 
influenced in any way (weather conditions of the growing season) and the second one -factors that can be controlled (plant nutrition, protection of plants from pests, diseases and weeds, and high-quality grain processing) [9-12].

As the studies have shown, under the influence of foliar dressing with the preparation Megamix-zinc, the protein content in the grain of spring wheat increased by $1.03 \%$ on average for 2018-2020 (Table 2).

Table 2. Protein content in spring wheat grain

\begin{tabular}{|c|c|c|c|c|}
\hline \multirow{2}{*}{ Variant } & \multicolumn{4}{|c|}{ Protein content, \% } \\
\cline { 2 - 5 } & $\mathbf{2 0 1 8}$ & $\mathbf{2 0 1 9}$ & $\mathbf{2 0 2 0}$ & Average \\
\hline Control 1 & 11.20 & 10.11 & 11.14 & 10.82 \\
\hline Megamix-zinc & 12.57 & 10.98 & 12.01 & 11.85 \\
\hline Control 2 + NPK & 12.57 & 11.43 & 12.17 & 12.06 \\
\hline Megamix-zinc + NPK & 12.91 & 11.71 & 12.66 & 12.43 \\
\hline
\end{tabular}

The combined use of the experimental preparation with nitroammophoska promoted a more significant boost in the protein content in the grain of spring wheat, which amounted to $1.61 \%$. This, naturally, is determined by more balanced fertilization of plants with mineral nutritive substances. Analysis of the dynamics of protein accumulation in spring wheat grain by research years shows that there is no significant difference in individual years. This is primarily connected with the fact that the weather conditions during the formation of the reproductive part of the plants were similar and did not differ significantly.

The most important feature that characterizes the baking quality of wheat grain is the gluten content and the criteria of its quality. The gluten content in grain is influenced by both internal and external factors: varietal characteristics, conditions of mineral nutrition, climatic conditions during the period of grain filling and formation. The gluten content increases with the application of nitrogen fertilizers, microelements.

As a result of the experiments, it was found that the mass fraction of gluten in the grain of spring wheat did not undergo significant fluctuations over the years of research, which can be explained by stable weather conditions and unchanged cultivation technology in these years.

However, the use of the preparation Megamix-zinc for foliar dressing, both in pure form and in contrast to mineral fertilization, contributes to an increase in the mass fraction of gluten in the grain of spring wheat. On average, over the years of studies, in comparison with the control variant, the increase was $1.57 \%$ (unfertilized plots) and $2.75 \%$ (fertilized plots), depending on the variant of the experiment (Table 3 ).

Table 3. Quantity of gluten in spring wheat grain of the variety "Ulyanovskaya 100"

\begin{tabular}{|c|c|c|c|c|}
\hline \multirow{2}{*}{ Variant } & \multicolumn{4}{|c|}{ Mass fraction of gluten, \% } \\
\cline { 2 - 5 } & $\mathbf{2 0 1 8}$ & $\mathbf{2 0 1 9}$ & $\mathbf{2 0 2 0}$ & Average \\
\hline Control 1 & 22.54 & 21.56 & 22.80 & 22.30 \\
\hline Megamix-zinc & 24.84 & 22.99 & 23.78 & 23.87 \\
\hline Control 2 + NPK & 24.99 & 23.11 & 24.61 & 24.24 \\
\hline Megamix-zinc + NPK & 25.97 & 24.09 & 25.10 & 25.05 \\
\hline
\end{tabular}

The most important indicator of the technological properties of gluten is its ability to form an elastic structure of the bread loaf interior under the influence of gas formation. In practice, the most used "elasticity index of gluten" is the GDI (gluten deformation index).

Analysis of the dynamics of the GDI in the grain of spring wheat by years of research showed a similar situation with the content of the mass fraction of gluten, that is, no significant changes are observed (Table 4).

If we analyze this indicator according to the variants of the experiment, we can say that the use of the preparation Megamix-zinc and the complex mineral fertilizer helps to reduce the gluten deformation index, which, in turn, improves the technological advantages of wheat grain. On average for 2018-2020 the GDI in spring wheat grain decreased by $4.44-6.47$ c.u. The best result was in the variant Megamix-zinc applied after nitroammophoska. It should also be noted that foliar dressing of spring wheat plants with the Megamix-zinc preparation promoted the formation of a gluten complex characteristic of wheat grains belonging to the first and second quality groups.

In wheat grain supplemented with microelements, the content of starch, the main reserve substance of endosperm, increases, which in the process of germination under the influence of $\alpha$ - and $\beta$-amylases decomposes to sugars used as a respiratory substrate during seed germination. When assessing the quality indicators of grain, which characterize the nutritional, feeding, and technological value of the final product of grain crops, it is advisable to take account of the starch content.

Table 4. Quality of gluten in spring wheat grain of the variety "Ulyanovskaya 100"

\begin{tabular}{|c|c|c|c|c|}
\hline \multirow{2}{*}{ Variant } & \multicolumn{4}{|c|}{ GDI, cond.units. } \\
\cline { 2 - 5 } & $\mathbf{2 0 1 8}$ & $\mathbf{2 0 1 9}$ & $\mathbf{2 0 2 0}$ & Average \\
\hline Control 1 & 81.08 & 79.77 & 80.45 & 80.43 \\
\hline Megamix- zinc & 77.14 & 74.87 & 75.98 & 75.99 \\
\hline Control 2 + NPK & 75.65 & 75.12 & 75.76 & 75.51 \\
\hline Megamix- zinc + NPK & 72.84 & 74.70 & 74.35 & 73.96 \\
\hline
\end{tabular}

It was found that under the action of the preparation Megamix-zinc and a complex mineral fertilizer, on average over the years of studies, the starch content in the grain of the experimental crop increased compared to the control variant by $2.64-4.99 \%$. The use of liquid mineral fertilizer Megamix-zinc in fertilized plots turned out to be the most effective (Table 5).

Table 5. Starch content in spring wheat grain of the variety "Ulyanovskaya 100", \%

\begin{tabular}{|c|c|c|c|c|}
\hline \multirow{2}{*}{ Variant } & \multicolumn{4}{|c|}{ Starch content, \% } \\
\cline { 2 - 5 } & $\mathbf{2 0 1 8}$ & $\mathbf{2 0 1 9}$ & $\mathbf{2 0 2 0}$ & Average \\
\hline Control 1 & 52.12 & 49.66 & 51.22 & 51.00 \\
\hline Megamix-zinc & 55.89 & 52.64 & 52.39 & 53.64 \\
\hline Control 2+ NPK & 56.49 & 53.71 & 52.76 & 54.32 \\
\hline Megamix-zinc + NPK & 58.14 & 55.19 & 54.63 & 55.99 \\
\hline
\end{tabular}




\section{Conclusions}

Thus, the use of growth regulators in the cultivation technology of agricultural crops permits one to optimize the mineral nutrition of plants, including trace elements, which ultimately ensures the actualization of their biological potential of productivity, their capacity to form high-quality products, and resistance to unfavorable growing conditions. In addition, growth regulators can reduce the sensitivity of plants to the lack of trace elements in the soil, thereby avoiding a decrease in yield.

The use assessment of the preparation Megamix-zinc and complex mineral fertilizers in the cultivation technology of the spring wheat variety "Ulyanovskaya 100 " showed that it was in this variant that the plants of the experimental crop formed the maximum yield with the highest protein content, mass fraction of gluten and starch. This agricultural technique can be recommended to optimize mineral nutrition and adapt plants to unfavorable weather conditions of the environment, increasing productivity and improving the quality of products obtained in the forest-steppe conditions of the Middle Volga region.

\section{References}

1. A.A. Zhuchenko, Adaptive potential of cultivated plants (Shtiitsa, Chisinau, 1980)

2. V.I. Kefeli, Natural growth inhibitors and phytohormones (Nauka, Moscow, 1974)

3. V.A. Kostin, Elements of mineral nutrition and growth regulators in ontogenesis of agricultural crops: monograph (Kolos, Moscow, 2006), 290 p.

4. E.D. Kazakov, Biochemistry of grain and products of its processing (Agropromizdat, Moscow, 1989)
5. B.A. Dospekhov, Method of field experiment with the basics of statistical processing of research results (Agropromizdat, Moscow, 1985)

6. The official website of Megamix, Retrieved from: http://megamix52.ru

7. V.A. Isaichev, N.N. Andreev, V.G. Polovinkin, The influence of macronutrients and growth regulators on yield and grain quality of winter wheat Kazanskaya 560 in the conditions of the Middle Volga region, Bull. of the Ulyanovsk State Agricult. Acad., 4(32), 13-18 (2015)

8. V.A. Isaychev, N.N. Andreev, F.A. Mudarisov, The influence of growth regulators and chelated micronutrients on the yield and quality indicators of peas and winter wheat, Bull. of the Ulyanovsk State Agricult. Acad., 1(17), 12-16 (2012)

9. I.A. Gaisin, Multifunctional chelated micronutrient fertilizers (Meddok, Kazan, 2007)

10. A.I. Pavlov, Increasing the protein content in grain (Nauka, Moscow, 1984)

11. O.A. Tkachuk, E.V. Pavlikova, A.N. Orlov, The efficiency of growth regulators' application in spring wheat cultivation in conditions of the forest steppe zone of the Middle Volga region, Young scient., 4, 677-679 (2013)

12. E.N. Shabolkina, A.P. Chichkin, Grain quality of new spring wheat varieties in the steppe TransVolga zone, Achievem. of sci. and engin. of Agroindustr. complex, 11, 29-31 (2009)

13. B.A. Yagodin, E.N. Maksimova, S.M. Sablina, Problems of trace elements in biology, Agrochem., 7, 126-134 (1988) 